\title{
Cultural relativity in \\ consumers' rates of adoption of artificial intelligence
}

\author{
Annie TUBADJI ${ }^{1}$, Toby DENNEY ${ }^{2}$, Don WEBBER ${ }^{3}$ \\ ${ }^{1}$ Swansea University, ${ }^{2}$ University of West of England, ${ }^{3}$ University of Sheffield
}

\begin{abstract}
Artificial Intelligence (AI) is a cost-efficient innovation that challenges customers' consumption patterns and fears of uncertainty. This study assesses whether the likelihood that consumers adopt $\mathrm{AI}$ in banking services depends on tastes across different cultures. We propose a culturally-augmented Arrow-Bilir-Sorensen model to assess the propensity that consumers use AI. Analyses of a unique ING Bank dataset encompassing 11,000 respondents from eleven countries reveal that success rates for the diffusion of robo-advisory financial services in retail banking vary substantially due to the cultural boundedness of choice. This bias seems to be associated with social capital rather than the fear of novelty.
\end{abstract}

Keywords: Diffusion of innovation; Social capital; Uncertainty; Culture-Based Development JEL classification: O33, Z10, G21 


\section{Introduction}

The adoption of artificial intelligence (AI) is intensely discussed lately in the economic literature, but mostly from the perspective of envisaged big efficiency gains for firms and the related labour market implications (Mullainathan et al., 2011; Autor 2015; Kim et al., 2016; Fisch et al., 2017; Ludwig, 2017; Morikawa 2017; Frey and Osborne 2017). This approach avoids considering earlier and related literature which suggests that: (i) new technology has an ambiguous effect on productive capacity (Bansak et al., 2007), and (ii) the diffusion of AI goods and services depends not only on firms propensity to offer them, but also on the propensity of people to adopt $\mathrm{AI}$ in their daily activity (as a reinterpretation of Rogers 1964 for the demand side).

In practice, based on firm surveys, it also seems that the decision to use AI does not depend simply on a general willingness of consumers to adopt AI in their daily activity, but also varies according to the particular type of activity concerned. In 2017 and across its consumer countries $^{1}$, HSBC bank found that its consumers trusted robots to do heart surgery twice as much as they trusted robots to provide financial advice (Mohan et al., 2017). Some other existing firm surveys for specific markets, highlight the importance of risk preferences and uncertainty avoidance in the customer's propensity to adopt AI.

Economic theory expects and supports the findings of these firm surveys, based on knowledge about economic behaviour with regard to information and uncertainty. The adoption rate of new technology is known to be influenced by the availability of information (Arrow, 2003, 2013; Arrow et al., 2017), since when information is incomplete, this creates uncertainty during the decision making process. The adoption of any innovative technology, especially breakthrough AI innovations, is clearly a decision making process under uncertainty. There is a global lack of information about AI technology's previous usage (Cont, 2006), thus uncertainty is unavoidable when making decisions that require the valuation of AI. Thus, bank consumers' level of information and experience with the use of technology will influence the uncertainty towards using AI, and will ultimately determine whether robotized bank services will be adopted successfully.

Moreover, the economic literature also knows that the importance of information and uncertainty is nuanced by the role and moderating effect of: (i) the decision maker's sensitivity to the context (as the context can stimulate or deter risk taking behaviours) (Rogers, 1964; von Hippel, 1988) and (ii) the underlying local culture (Nelson and Winters, 1982; Ajzen, 1991). On personal level, the adoption of a technology is known to be influenced by attitudes towards fears

1 The HSBC study included 12,019 respondents from 11 countries (Canada, China, France, Germany, Hong Kong, India, Mexico, Singapore, United Arab Emirates, United Kingdom and the US). 
of the unknown, stemming from bounded rationality driven by cultural beliefs which institutionalize old knowledge and maintain the socio-economic discourse (Shackle, 1949). On aggregate level, the local cultural context may significantly shape adoption rates of innovative technologies per se. It can lead to either the Schumpeterian destruction of existing socioeconomic local standards (Aghion and Howitt, 1992) or the rejection of new technologies in the local market due to uncertainty surrounding the potential costs from its adoption (Knight, 1921; Shackle, 1949; Amoroso et al., 2017). Thus, since average risk preference and uncertainty avoidance vary across cultures, the reaction of the market to AI is likely to be spatially heterogeneous (Mansfield, 1968; Scitovsky, 1976; Jensen, 1982; Hanh, 2014; Savini, 2017) on both individual and aggregate level.

This study investigates the extent that uncertainty surrounding the use of AI influences a local market's predispositions towards valuing and eventually adopting AI in banking services. Specifically, we test the hypothesis that the variation in open-mindedness related attitudes across cultures shapes the differences in local consumers' predispositions towards the propensity to adopt AI. Thus, this study is the first to examine the consumer adoption rate of robo-advisory AI in banking services under conditions of uncertainty and it offers important implications for the adoption of AI across different cultural contexts.

Our empirical work draws on a database, provided exclusively to us by ING Bank, which contains survey data from 14,000 consumers across the fourteen countries in which they operate. We combine the ING Bank data with World Value Survey (WVS) information on countryspecific attitudes and explore the effects of individual characteristics and local bias on the local market's economic preferences towards AI adoption in retail banking. Data availability from the WVS reduces the exploration to eleven countries. We employ regression analysis (contrasting the use of country fixed effects and local level variables with culture-related variation) and estimate a hierarchical (multi-level) regression model. The results are important for the banking sector, and the service sector more generally, as they emphasise the role of cultural relativity as a barrier in adopting AI. This barrier is especially strong in places where strong social capital and high consumer satisfaction already co-exist. Our findings show in particular that lower social capital (measured as the fear from being cheated) is an important factor that reduces consumers' preference to adopt $\mathrm{AI}$ in banking services.

This is the first study that assesses the willingness of consumers to adopt robo-advisory technology in the banking sector. Such knowledge is crucial for shaping strategies for the successful assimilation of AI into any market. We pay particular attention to the variation in the openness of consumers to adopt AI across countries and the sensitivity of this adoption to cultural relativity. Our focus is on an important category of AI, robo-advisory services in the 
banking sector, where robo-advisory is defined as "automated investment platforms that provide investment advice without the intervention of a human advisor" (Lam and Swensen, 2016).

This study has the following structure: the next section reviews the academic literature on the known biases in the rate of technological adoption that exists across cultures. In response to our research question, we sought data and generated an estimation strategy, details of which are contained in section 3. Section 4 presents and interprets the results, while section 5 concludes.

\section{Technological adoption and cultural bias}

This research assesses whether individuals clustered into localities and markets exhibit cultural homogeneity of their tastes and preferences, and therefore whether different markets and localities exhibit different aggregate tastes for the adoption of the same piece of innovative technology. This reasoning entails two aspects: the role of the information/uncertainty ratio, and the role of local culture in the adoption of new technology.

Classical theory suggests that technological adoption is initiated partially by available information. Arrow's (2013) adoption mechanism presents a process of information diffusion where the demand for undisclosed information is undefined. Leppälä (2013) adds that the value of information for the buyer depends on its relevance, and the seller needs to reveal relevant information to its consumers in order to optimise price. For instance, banks need to know which AI functions and capabilities to provide to their consumers when attempting to sell financial products, especially when firms are trying to convince consumers to use cost-saving AI and when firms set prices.

A competing perspective proposed by Arrow, Bilir and Sorensen (2017) argues that delays in adoption depend on the time of access to information about the innovation. We shall elaborate the details of this model in our empirical strategy. In addition, Rogers (1964) emphasised that there are five categories of adopters: innovators, early adopters, early majority, late majority, and laggards. In the presence of such heterogeneity in adoption, retail banks must identify the needs of each adopter category in its consumer base and understand how each consumer category interacts with AI characteristics. Although there are important differences in innovation adopting behaviours across individual consumers, there are also important aggregate differences in innovation adopting behaviours across markets (Restuccia and Rogerson, 2017). Questions then emerge whether groups of consumers in different countries behave in different ways and what influences the variation in consumer adoption rates of AI across countries. Merging the above 
ideas leads to a holistic model that incorporates temporal arrangements across heterogeneous groups of individual adopters.

Cultural norms are recognised as a significant cause of asymmetries in the handling of uncertainty (Hall, 1966; Tubadji et al., 2020) and the presence of heterogeneous consumer adoption behaviours across countries is likely to be related to cross-cultural differences in attitudes to uncertainty. Klasing and Milionis (2014) find that intergenerational transmission of patience as a cultural trait influences significantly the local potential for innovation and growth. Tubadji and Nijkamp (2016) found that the cogitation of innovative investment ideas could be prevented if the local culture is not sufficiently open to novel ideas. But even if an innovative idea manages to percolate through the cultural lattice and become realised, the adoption, replication and diffusion of the idea remains dependent on the degree of connectedness of local social and business networks (Moody, 2002; Jackson, 2014) with network connectedness also being culturally-dependent (Verdier and Zenou, 2017).

Beyond attitudes to uncertainty, many examples illustrate the effect of cultural bias on economic choice. Cultural biases are known to affect preferences for types of income distribution (Acemoglu et al., 2002), gender roles (Alesina et al., 2013), developments of institutions (Alesina and Giuliano, 2015), developments of financial institutions in particular (Grosjean, 2011; Ang, 2019), crime (Grosjean, 2014), corruption and tax evation (Ivanyna et al., 2016), competitiveness (Leibbrandt et al., 2013), economic productivity (Knack and Keefer, 1997; Guiso et al., 2006; Tabellini, 2010), economic flows and exchange (Zak and Knack, 2001; Guiso et al., 2009), employment (Moriconi and Peri, 2015), pension schemes (Galasso and Profeta, 2018), work culture (Eugster et al., 2017) and socio-economic development (Costa-Font and Macis, 2017). Culture seems to pervade all economic systems, making it unlikely that the banking sector is spared from this powerful cultural effect.

\section{Adoption of innovations in banking services}

The effect of uncertainty on the adoptions of innovations operates within the domain of bounded rationality. The financial sector, and banking in particular, has been widely documented as a market exhibiting bounded rationality. Rogoff (1999) states that "there are biases in the existing system towards debt finance and bank intermediation, at the expense of equity finance and direct investment". Recalling the limitations of probability intimated by others (Pigou, 1927; Keynes, 1936; Collard, 1983), Akerlof and Shiller (2009) reveal an even more complex understanding of human boundedness in financial decision-making where the link between emotions and the business cycle rests on a set of psychological factors including confidence, fairness, corruption, 
money illusion and stories. ${ }^{2}$ The bounded rationality of individual banking consumers is recognised in cases of innovation other than $\mathrm{AI}$ adoption, such as borrowing and lending, with banking innovations known to be able to offset consumers' bounded rationality shortcomings (Berger, 1996; Frame and White, 2004; Akhavein et al., 2005; Dabla-Norris et al., 2012).

The financial literature that encompasses cultural effects includes analyses of home bias effects of foreign direct investment and greenfield investments (e.g. Tadesse and Shukralla, 2013), financial flows, the role of cultural distance in investment choice, and the provision of banking services in different geographic localities. A prime example is Demirgüç-Kunt and Kane (2002) who reveal a different perspective on innovation and adoption by stressing that an innovation does not necessarily function with equal levels of success in different institutional contexts. Similarly, Hahn (2014) assessed Austria's local and regional banks' lending patterns to consumers in neighbouring Eastern European countries and shows how a common cultural heritage affects cross-border loans.

Although less common, there are investigations of the effects of bounded rationality on the demand for innovative bank products. Benston (1994) highlighted the reluctance of US and German bank consumers to exploit banking services even though doing so would objectively reduce monetary- and time-related transaction costs. Restuccia and Rogerson (2017) investigated consumers' bounded rationality expressed as the misallocation of resources and innovation diffusion delays across developed and less developed countries. However, these studies do not sufficiently develop their examinations of the cultural factor that underpins the bounded rationality of banking consumers' openness to innovations.

Although the literature documents that different locations naturally have their own cultural milieu and attitudes (Akerlof, 1997; Akelof and Kranton, 2000, 2010; Acemoglu and Robinson, 2012), our study is the first to capture the cultural relativity of consumers' tastes for AI/robo-advisory services in the financial sector. We build on the work of Fehr and Hoff (2011) who argued that preferences are not exogenous to psychological factors that connect choice to beliefs because society and social interactions influence the decision maker's psychology. Similarly, Kontot et al. (2016) studied consumers' motivations and preferences to deposit money into Islamic banks and revealed a set of important factors including Sharia compliance, the human touch, and zakat ${ }^{3}$, which are integral to the cultural element of Islamic banking. To combine the above insights on the role of uncertainty, culture and psychology into our understanding of the socio-economic process of innovation and local development, this study

2 Stories and narratives play a central role in triggering economic bubble effects (Akerlof and Shiller, 2009; Schiller, 2017) and the stories that everyone starts telling and believing subsequently generate a self-fulfilling prophecy.

${ }^{3}$ Inspired by one of the Five Pillars of Islam related to alms giving, zakat is a form of an annual tax on certain kinds of property which is aimed to finance charitable and/or religious purposes. 
adopts the Cultural-Based Development (CBD) perspective as a paradigm underlying our analysis. The CBD postulates that society and social interaction influence psychological factors and development (Tubadji, 2012, 2013), where the percolation of new ideas depends on social interaction and its channels for the exchange of information (Tubadji and Nijkamp, 2016). Hence, the CBD approach stresses that since information is important for the adoption of technology and culture plays an important role in the exchange of information, it follows that culture is significantly determining the probability of adopting innovations.

\section{AI in banking services}

$\mathrm{AI}$ is hard to define because it is under development. The computer science field defines AI as a decision making agent that acts intelligently: what it does is appropriate for its circumstances and its goal; it is flexible to changing environments and changing goals; it learns from experience; and it makes appropriate choices given perceptual limitations and finite computations (Poole $e t$ al., 1998; Nilsson, 1998). AI is classified within the economics literature according to the complexity of the task and the type of workers' tasks that AI can replace (e.g. simple and complex or industrial and service). The main reason for this stance is the $\mathrm{ALM}^{4}$ hypothesis (Autor et al., 2003; Autor, 2013, 2015) which deals with the substitutability of workers for AI.

Research on the labour market effects of AI has been developing vigorously over the last decade in spite of the fact that AI has been developing extremely fast and it is very difficult to predict with accuracy the impact of an entity whose definition changes with time (Susskind, 2017). Theoretical and empirical research into the effects of AI on employment exist but are inconclusive, with estimates varying from very pessimistic ${ }^{5}$, to reassurance ${ }^{6}$, to very optimistic ${ }^{7}$. However, all these articles are only concerned with AI as an input into the production process and there remains a gap in the literature concerning whether consumers will demand and adopt AI. This paper fills part of that gap by examining the willingness of consumers to adopt new AI technology and whether consumers will interact with it in an efficient, cost effective manner. Our study presents an assessment of the openness of consumer demand to the adoption of AI in retail financial services in a cross-section of countries, and in particular the association between cultural relativity and the variation in consumers' cultural openness to AI adoption.

\footnotetext{
ALM is an abbreviation of the initials of 'Autor, Levy and Murnane' who co-authored Autor et al. (2003). Acemoglu and Restrepo (2017) found that "one more robot per thousand workers reduces the employment to population ratio by about $0.18-0.34$ percentage points and wages by $0.25-0.5$ percent."

6 Lehmer and Janser (2018) found that the effect of AI seems to be similar to a simple technological innovation.

7 Caselli and Manning (2017) claimed that all workers can experience and increase in their wages if the AI increases overall productivity and workers change occupations.
} 


\section{Data and method}

This study merges two datasets: the ING Bank Consumer Monitor (2017) and the World Value Survey (WVS). ING Bank provided us with access to the first dataset, which was collected as part of their 2017 Mobile Banking Survey and contains over 80 questions and details of 14,000 respondents from fourteen countries. ${ }^{8}$ The ING dataset was collected using internet-based polling and questions relating to experiences with technology and banking, the clients' current use of cash, and their opinions on the concept of robo-advisory services. The survey captures consumers' preferences to pay with cash or card in certain situations, and consumers' perceptions of their expected reliance on cash in the future. We augmented this ING dataset with area-level attitudinal information obtained from the WVS. Merging the datasets reduces the number of countries that we are able to empirically investigate to eleven (due to missing observations) but it does enable the analysis of information on four themes: social values, corruption, security and ethical values. The WVS is an amalgam of representative national surveys that quantify the attitudes on the above four themes across social cultures and countries.

\section{ING Bank dataset}

Our main dependent variables relate to the propensity to use robo-advisory services in banking and are labelled $R O B O \_F A N \_c o u n t$ and $R O B O \_F A N$, where the latter is a dichotomous variable based on the former. These variables draw on the question "Would you allow a robo-advisor to make financial decisions for you?" which has a five-point Likert scale answer scheme reflecting different degrees of willingness to use robo-advisory services. ROBO_FAN has a value of 1 (one) if the bank consumer answered "Yes, if the decisions need final approval from me" or "Yes, I would like a computer programme to make decisions and conduct financial activities for me on my behalf without needing my approval", and 0 (zero) otherwise.

Our main explanatory variables are $Q U A N T I T Y \_U S E$ and ACCESS_BEFORE_2014. QUANTITY_USE draws on two questions: (i) whether the consumer uses a mobile phone, a smart phone, a tablet, a smart TV, and/or an Apple wearable device, and (ii) whether the consumer has used these devices for online banking. If the respondents confirmed that they owned a specific device and used that device for online banking then this variable takes a value equal to 1 (one) and 0 (zero) otherwise. We sum the interactions across the devices for each

8 All countries (except Luxembourg) have equal weighting with about 1,000 (500) respondents. 
person. The sum of these interactions per person allows us to generate a variable called QUANTITY_USE, which reflects the quantity of devices used for online banking by the individual. The variable ACCESS_BEFORE_2014 is a dummy variable equal to 1 (one) if the individual used online banking before the year 2014, and 0 (zero) otherwise. This dummy variable is based on the question 'How long have you been using online banking?' which has four answers: before 2014, since 2015, 2016, or 2017. We use this variable also as a categorical variable called TIME_ACCESS where 2017 is equal to 1, 2016 to 2, 2015 to 3, and before 2014 to 4. A range of demographic control variables were extracted from the ING data, including gender (MALE), employment status (RETIRED, STUDENT, FULL_TIME, PART_TIME, and SELF_EMPLOYED) and AGE. Besides the actual age of the respondent, we also create a dummy variable called $A G E \_M I L L E N I A L S$, which is equal to 1 (one) only for people whose age was between 18-35. Existing literature suggests that millennials are the prime age group who would engage with robo-advisory services (see for example Fein, 2017). We use age and age squared as regressors to assess if the patterns of propensity to adoption of AI technology change with the progression of age.

Dichotomous country identifiers are included for each respondent: $A U, A U S, C Z, F R, D E$, IT, LUX, NL, PL, RO, ES, TR, UK and USA. ALONE is a dichotomous variable based on a question about the number of people living in the household with the respondent. $H C$ and $E D U \_N O N E$ are variables based on the question that captures the respondents' educational level, with a range from no education, General Certificate of Secondary Education or equivalent, Higher National Diploma or equivalent, A-Level or equivalent, to Bachelor's degree and above. $H C$ is a dichotomous variable which indicates that the respondent has a university-level qualification. Finally, RATHER_CASH is a variable based on the question "Would you rather shop somewhere that only accepted cash or card?" and is used to understand whether someone is more traditional and uses cash rather than being inclined towards using only electronic payments and credit/debit cards; this variable is equal to 1 (one) when the individual reports preference to use cash over card, and 0 (zero) otherwise.

\section{World Value Survey}

The WVS survey focuses on the differences in attitudes across geographical locations. Five attitudes were extracted from this survey where the values correspond to the share of respondents per country who strongly supported the attitude, as indicated by a value of 7 or more on a 10point Likert scale. These cultural value $(C V)$ attitudes correspond to the openness to new ideas (SHARE_PRO_NEW_IDEAS), views on whether scientific advances are useful 
(SHARE_SCI_ADV_USEFUL), trust in people (SHARE_TRUST_PPL), feelings that others may easily take advantage of them (SHARE_TAKEN_ADV_OF), and wanting to feel in charge of their own life (SHARE_IN_CHARGE).

\section{Descriptive statistics}

Definitions and descriptive statistics of all variables are presented in the Appendix. Our final sample is comprised of just over 11,000 consumer observations because the WVS was not available for three countries that were included in the ING Bank dataset (namely Austria, Belgium and Luxembourg). For the available countries, the sample was reduced further only when we try to focus on count data, where people were excluded from the sample if they could not identify their preferences and in cases where income and time of access to online banking observations were missing. The average age of consumers is 44 years, 39 percent of consumers have a university education, and the sample splits evenly between gender.

About 20 percent of consumers expressed a high propensity to use robo-advisory services in their banking activity and only 21 percent of consumers had access to online banking before the year 2014, which support the mechanisms behind the Arrow-Bilir-Sorensen (2017) model and our adaptation of it for the propensity to use the robo-advisory platform. Cultural attitudes vary significantly in the data: while appraisals of the advantage of science and desires to rule one's own destiny (both reflecting attitudes to uncertainty) spread roughly equally among the population, positive attitudes relating to trust are shared by only 28 percent. The strong negative attitudes to trust and the openness to new ideas represent less than 20 percent of the population in the countries in our sample.

\section{Estimation methods}

We first consider the individual predispositions to use robo-advisory platforms and then augment the model to include cultural factors. We alternate between using country fixed effects and cultural attitudinal variables to obtain and strengthen intuition about how much the cultural factor affects the overall performance of our model. Finally, we estimate the importance of cultural variation across local markets within a hierarchical model to explain variations in the propensity to adopt robo-advisory platforms in the banking sector. Inspired by Coleman et al. (1957), we adopt the Arrow, Bilir and Sorensen (2017) (ABS) model and modify it to account also for the cultural propensity of the bank consumer to adopt robo-advisory platforms. 
The original ABS model expresses the duration of time to adoption of a newly released drug by a particular doctor as a function of the doctor's access to a database with information about the drug, the doctor's total prescription volume, and doctor and locality fixed effects. Their econometric model can be re-stated as:

$$
N E W \_D R U G \_F A N \_c o u n t=\eta \_A B S+\beta_{1} Z \_A B S+\beta_{2} N \_A B S+e
$$

where $N E W \_D R U G \_F A N \_c o u n t$ is the propensity to adopt a new drug (i.e. probability of starting to prescribe it) by a doctor within twelve months of release of the new drug; $\eta_{-} A B S$ is a vector of fixed effects for zip-code (related to drug) and physician; $Z \_A B S$ indicates whether the doctor has access to the database at the time when the drug is first introduced, and $N \_A B S$ is the doctor's total prescription volume for drugs in the month preceding the introduction of the drug. In a nutshell, the ABS econometric model expresses the propensity to adopt a drug as a function of the time of access to the electronic database and the volume of prescribing a similar type of drug preceding the invention of the new drug.

We retain the essence of the ABS model but modify it to explain the propensity to adopt AI in banking services (rather than the propensity to adopt a new drug). This propensity to adopt $\mathrm{AI}$ is a function of the time of access to electronic banking services (rather than the doctor's time of access to the drug database) and the volume of other digital appliances that the bank customer employs in their daily online banking themselves (rather than doctor's total prescription volume of drugs similar to the novel drug), such that:

$$
R O B O \_F A N \_ \text {count } i=\eta+\beta_{1} Z_{i}+\beta_{2} N_{i}+\beta_{3} X_{i}+e_{i}
$$

where $R O B O \_F A N \_c o u n t$ is the propensity to adopt robo-advisory banking services for individual $i, \eta$ represents country fixed effects (as we use a cross section we cannot include individual fixed effects, as the ABS model required), $Z$ is a dummy variable reflecting the bank consumer's use of online banking services from before 2014, and $N$ is the quantity of digital appliances used by the individual for banking needs. $X$ stands for a set of relevant control variables (as our dataset contains more information about the individual than in the ABS model). First, we estimate this model using OLS with robust standard errors. Second, we transform the dependent variable from the OLS into a dichotomous variable, ROBO_FAN (where the value of 1 (one) indicates a declared interest in using robo-advisory banking services) and we re-estimate the regression using a Probit model. 


\section{A CBD model of innovation adoption rates}

Our CBD model reflects the need for an assessment of the universality of values involved in choosing to accept robo-advisory facilities. The CBD model advocates that differences in attitudinal norms that exist between localities and cultures are the main drivers of differences in individual socio-economic choices between localities and cultures (see Tubadji 2020). In the case of AI banking services, the CBD model corresponding to the propensity to use roboadvisory facilities is:

$$
R O B O \_F A N \_ \text {count } i=\beta_{1} Z_{i}+\beta_{2} N_{i}+\beta_{3} X_{i}+\beta_{4} C V+e_{i}
$$

where $C V$ (cultural value) is the local aggregate share of people who strongly support a particular type of attitude relevant for the adoption of AI / robo-advisory in banking services. This locally specific share of support for an attitude is a proxy for the local cultural milieu in which the decision maker is situated. ${ }^{9}$

\section{Hierarchical CBD model}

The CBD theoretical model builds on Adam Smith's ideas of the Impartial Spectator, i.e. an internal code of what is right and good. CBD theory expects that there exist cultural deviations in local ethics that create locally specific perceptions of the Impartial Spectator (Tubadji 2020). Hence, people from different cultural backgrounds may experience the same attitude but with a different level of affect. CBD suggests that every locality has a locally specific Impartial Spectator affect with its own local ethical code and its own unique deviation from the natural, global moral. This CBD proposition inspires the following robo-advisory adoption-related mixed effects model (i.e. a hierarchical, variance components model):

$$
R O B O \_F A N_{i}=m+e_{\text {country }}+e_{\text {world }}
$$

where $m$ is the fixed component, explained by a vector of variables corresponding to the explanatory variables in model (2) relating to the Arrow-Bilir-Sorensen model (2017); $e_{w o r l d}$ and $e_{\text {country }}$ are the random components of the hierarchical model and represent the variation due to

9 This model is based on Tubadji $(2012,2013)$ with the country fixed effect, $\eta$, being omitted here because $C V$ is at the country level. Using $C V$ brings more precise estimation since it accounts quantitatively for the reason why the fixed effects exist. 
the nesting of the data in countries and their local cultures. Component $e_{w o r l d}$ denotes deviations from the grand mean of all observations, while $e_{\text {country }}$ captures the standard deviation from the mean within country clusters. ${ }^{10}$

\section{Results}

Table 1 presents the OLS and Probit results corresponding to six alternative specifications of model (2). These specifications explain the propensity to adopt robo-advisory services with the length of time of exposure to online services and the volume of alternative technologies used by the individual. Specification 1 uses the standard specification of model (2) where the two control variables are: a dummy variable for living alone and a dummy variable for being retired. Specification (2) substitutes the explanatory dummy variable from Specification (1) regarding the access before year 2014, with a variable reflecting the length of time of access to online banking. This length of time of access variable has four categories according to the starting year of use, respectively: before 2014 (corresponding to the variable's value of 4), since 2015 (value of 3), since 2016 (value of 2), or since 2017 (value of 1). Specification 3 includes income, Specification 4 includes an additional control for being a student, and Specification 5 adds a control for working part time. Specification 6 tests model (2) by transforming the dependent variable into a dummy variable equal to 1 when a high propensity to use robo-advisory services is declared by the consumer. The last specification is the only one in which we use a Probit estimator and we present for it the marginal effects at mean values. All OLS and Probit estimates use robust standard errors.

\section{$\{$ Table 1$\}$}

The main components of model (2) - time of access to online banking and the volume of electronic tools used for electronic banking - are both statistically and economically significant factors, explaining the propensity of consumers to adopt AI in banking services. Yet, the volume of electronic tools has the more powerful effect. This finding is consistent with the perspective

10 For more details on identification, see Tubadji $(2018,2020)$ where this model was first proposed for CBD use. Statistically speaking, if we consider a linear regression model in matrix form as $y=X \beta+e$, a hierarchical model accounts for: $y_{j}$ the vector of observations in group $\mathrm{j} ; \beta$ the vector of fixed parameters (with components $\beta_{1}, \beta_{2}, \ldots$ ); $b_{j}$ the vector of random effects for group $j$ (with components $b_{1 j}, b_{2 j}, \ldots$ ) and $e_{j}$ the vector of random errors for group $j$. Then, any hierarchical linear model (with one level of grouping) can be expressed as: $y_{j}=X_{j} \beta$ $+Z_{j} b_{j}+e_{j}$, where the matrices $X_{j}$ and $Z_{j}$ are the known fixed-effects and random-effects regressor matrices. In our specified model (4), $\mathrm{X}_{\mathrm{j}}$ relates to $m$ and $\mathrm{Z}_{\mathrm{j}}$ relates to $e_{\text {country }}$, while $\mathrm{e}_{\text {world }}$ is the vector of random errors. See also Goldstein and Rasbash (1996), Gelman and Hill (2007) and Snijders and Bosker (2012) for more details. 
that income and human capital are both positively correlated with the propensity to use AI due to being better educated, better informed about AI, less rationally bounded away from new technology, and having higher abilities to purchase and possess digital tools.

Additional controls, such as employment, student status or retirement, do not seem to significantly affect the propensity to use AI, whereas living alone seems to have explanatory power when the most extreme category of the propensity to use AI is explored in Specification 6. Demographic controls of age and gender are highly statistically significant across all specifications. We find that men are more inclined to adopt AI, which perhaps is due to social construct effects, as men are socially expected to engage more with technology and because they have a lower level of risk aversion (Borghans et al., 2009). The results however may reflect either a real difference in the propensity or only a self-reporting bias with male respondents declaring a higher propensity on average. The two effects cannot be distinguished here. The shape of the relationship between age and the propensity to use AI is inverted-U shape. This points to a Kuznets's curve-type relationship where middle age consumers are richer and more inclined to save, but are also the most heavily time-burdened, intimating that AI use may save time and this may drive the use of AI. ${ }^{11}$ The overall explanatory power of the model, however, is only 12 percent, so we proceed to include a cultural variable as this could add further explanatory power to the model instead of simply allowing for unwanted heterogeneity and clustering of individual observations through the use of country-level fixed effects.

\section{Evidence from a CBD model: robo-advisory and culture}

We extended model (2) to include a proxy for the local cultural milieu, which captures the effects of the individuals' local context. Table 2 provides five different proxies for local culture to be explored as a factor explaining choice: the share of people open to new ideas, the share of people praising scientific advancement, the share of people who have high levels of trust in people (i.e. high social capital), the share of people who are afraid of being taken advantage of (i.e. low social capital), and the share of people who feel in charge of their destiny (since using $\mathrm{AI}$ is, in a sense, delegating one's decision to a machine). We include both of the social capital variables since Prospect Theory suggests that the fear of loss should be twice as important as a corresponding positive sentiment (Kahneman and Tversky, 1979).

11 Alternatively, this inverted U-shape curve may reflect a special role of the millennial generation. To cross-check this explanation we calculated the inflection point of this U-shaped curve and it lies between 32 and 38 years, which is outside of the millennial age and may be associated with the average age of people in the peak of their career development. Thus, we find our Modigliani-type interpretation finds more support in the data than the millennial hypothesis. 
Our results confirm the findings from Table 1 and the age with the highest propensity to use AI narrows its variation to between 33 and 36 years. Each cultural variable has a different economic and statistical importance. Openness to new ideas and a longer experience of using online banking both have a negative effect on the propensity to adopt AI, which is consistent with Argote et al. (1983) who found that over time, the experience of workers using robots became more pessimistic about the robots due to the way the robots changed the nature of their team interaction and added more stress into the work process. Moreover, it seems plausible that the novelty of AI fades away faster for people who are open to novelty. Once they gain experience with the AI service, they get tired of it faster than the average consumer. Greater trust in people seems to be associated with lower propensity to use AI and this effect is half the size of the fear of being cheated effect, which is consistent with findings from game theoretical examples, where robots were perceived as more reliable than people and not able to cheat (Torta et al., 2017). Taken together, these results are consistent with Prospect Theory and give a sign that the presence of social capital and loyal consumers are not effective indicators of the likely success rate of introducing AI into banking. Hence, AI in banking might flourish and be readily adopted only when and where consumer loyalty and inter-personnel relationships have low importance.

The explanatory power of the model does not increase with the introduction of cultural variables, which may not capture the entire cultural milieu. ${ }^{12}$ Some of our individual control variables, especially living alone, become significant when cultural clustering is accounted for in a quantitative manner and not just captured using country fixed effects, suggesting that applications of a hierarchical regression model may be appropriate.

\section{Hierarchical CBD model}

The results from our hierarchical model estimations, shown in Table 3, indicate that the fixed part (explaining the individual propensity to use robo-advisory by individual characteristics, apart from accounting for country-clustering) is consistent with results in Tables 1 and 2. The interval within which the age maximum lies narrows to between 34 and 36 years. Regarding the random component, as seen from the coefficient of $s d\left(\_c o n s\right)$ in Table 3, Specification 1, country level effects account for 20 percent of the deviation from the grand mean for the

\footnotetext{
12 We conducted several additional tests, including using a Probit model after transformation of the main dependent variable and using fixed effects but the explanatory power remained the same.
} 
propensity to use robo-advisory services. When we try to explain stochastically the withincountry variation by approximating local culture with different attitudes from the WVS, we find that culture is always a strongly statistically significant predictor of the nesting of individual preferences concerning the use of robo-advisory services. However, the size of the cultural effect in the nesting of individual preferences within localities varies across the cultural variables. The fear from being cheated has twice the (positive) strength in enhancing consumers' preference to use AI than is the (negative) effect of a trust in people which repels the use of AI. At times, the cultural proxy almost completely accounts for the country effect, and this confirms previous findings within the CBD literature that culture is best quantified as a vector variable rather than as a single dimension variable (Tubadji, 2014), which points to the consistency of the CBD model with Prospect Theory. Put differently, we observe that the different cultural attitudes have a different magnitude of effect on the outcome variable. This confirms the alert posed by Tubadji (2012; 2013) that using a cultural proxy might not be sufficient to capture the entire cultural impact, as culture is a complex entity. Future research on the cultural relativity of consumers' adoption rate of AI might benefit from using not only alternative cultural proxies, but instead some composite cultural measures, as usually recommended by CBD, if they aim at accounting most efficiently for the exact amount of the cultural relativity of the consumers' propensities. The coefficients of all regressors change due to the switch to a hierarchical model; this demonstrates that the cultural clustering is indeed an important factor for the variations of all variables in the model and it needs more precise handling.

$\{$ Table 3$\}$

\section{Conclusion}

This study explored the reasons why bank consumers located in different markets and situated in different cultural contexts have different propensities to adopt AI in bank service provisions. In contrast with the existing literature that focuses on the supply side of the market, our analysis focuses squarely on the demand side and specifically on consumers' propensity to adopt AI in the banking sector. The literature has acknowledged the importance of bounded rationality affecting consumers' use of new bank services and the macro-behavioural finance literature has recognised the aggregate boundedness of people. Yet, no existing study analyses the rate of adoption of AI with an explicit recognition of the importance of culture even though a cultural bias is known to exist in financial decision making, such as in analyses of the effect of home bias on investments. This is the first study to link bounded rationality and culture in an assessment of the consumer decision to use $\mathrm{AI} /$ robo-advisory services in banking. 
Using a unique database from ING bank that was merged with WVS data reflecting local cultural contexts, this study presents an adaptation and augmentation of the Arrow-BilirSorensen (2017) model to empirically examine the existence of bounded rationality and cultural asymmetries in consumer decision making about the use of AI and robo-advisory services.

Our results reveal several additional insights not currently embedded in existing literature and these relate to the culturally-informed taste for AI. First, among various culturally specific attitudes, local levels of trust perform a prime role in driving the inclination of consumers to use AI. These results corroborate the findings by Greenwood and Scharfstein (2013), who suggested that the critical question is not whether active management leads investors to earn excess returns, but instead whether the pursuit of excess returns produces social benefits. Specifically, the introduction of AI cannot be guaranteed to be successful in engendering AI engagement just because it is more efficient for the bank. AI-based supply can turn out to be successful only in cases where it compensates for feelings of a lack of trust and reliability towards human advisors among its consumers.

Second, a key finding is that the fear from being cheated (i.e. the lack of social capital) is a factor that has a stronger influence in enhancing consumers' preference to use AI than the strength of trust in people. This result corroborates the suggestion by Bansak et al. (2007) that there are many ambiguities behind the impact of modern technology on productivity and efficiency. It is also in general agreement with the recommendation of Shin and Subramanian (2019) that 'lean against the wind' policy is not always the most preferable investment rule regarding innovations. Our study suggests alternatives to this previous research with the view that raising awareness of the benefits of $\mathrm{AI}$ in environments with high trust levels may be effective in attracting consumers to use AI. However, this finding should be treated with caution since openness to new knowledge and longer exposure to the use of online banking (i.e. previous experience with AI-related technologies) seem to be negatively associated with the propensity to use AI. Until this relationship is disentangled, it would be safer for banks to focus their introduction of AI and robo-advisory services into markets where a lack of trust and bank loyalty is an existing problem.

Although the empirical results presented in this study are based on a large number of customers spread across eleven countries, there remains a need for replications of this study, as the data are drawn from one large international bank that does not have offices in all countries of the world. Further research is needed to identify the rate at which these seemingly vitally important cultural effects evolve in importance and potentially correspond asymmetrically to each specific advance in AI. In spite of the existence of these concerns, this study is the first 
relevant analysis to shed some light on consumers' determinants in the adoption of AI and should inform the spatial rollout of consumer facing investments in new innovative technologies.

\section{References}

Acemoglu, D. and J. Robinson. Why Nations Fail: The Origins of Power, Prosperity, and Poverty, Crown Publishing Group. 2012

Acemoglu, D. and P. Restrepo. "Robots and jobs: evidence from US labor markets”, NBER Working Paper \#w23285. 2017

Acemoglu, D., D. Cantoni, S. Johnson, and J. Robinson. “The Consequences of Radical Reform: The French Revolution.” American Economic Review, 101, 2011, 3286-3307.

Acemoglu, D., S. Johnson and J.A. Robinson. "Reversal of fortune: geography and institutions in the making of the modern world income distribution.” Quarterly Journal of Economics, 117(4), 2002, 1231-94

Aghion, P. and P. Howitt. “A Model of Growth Through Creative Destruction.” Econometrica, 60(2), 1992, 323-51

Ajzen, I. “The Theory of Planned Behavior.” Organizational Behavior and Human Decision Processes, 50(2), 1991, 179-211.

Akerlof, G. and R. Shiller. Animal Spirits: How Human Psychology Drives the Economy, and Why it Matters for Global Capitalism, Princeton: Princeton University Press. 2009.

Akerlof, G.A. “Social Distance and Social Decisions.” Econometrica, 65(5), 1997, 1005-1027.

Akerlof, G.A. and R.E. Kranton. "Economics and identity.” Quarterly Journal of Economics, 115(3), 2000, 715-33

Akerlof, G.A. and R.E. Kranton. Identity Economics - How our Identities Shape our Work, Wages, and WellBeing, Princeton, NJ: Princeton University Press. 2010.

Akhavein, J., W. Frame and White. "The Diffusion of Financial Innovations: An Examination of the Adoption of Small Business Credit Scoring by Large Banking Organizations.” Journal of Business, 78(2), 2005, 577-596

Alesina, A. and P. Giuliano. “Culture and Institutions.” Journal of Economic Literature, 53(4), 2015, 898-944

Alesina, A., P. Giuliano and N. Nun. “On the Origins of Gender Roles: Women and the Plough.” Quarterly Journal of Economics, 128(2), 2013, 469-530.

Amoroso, S., Moncada-Paternò-Castello and A. Vezzani. "R\&D Profitability: The Role of Risk and Knightean Uncertainty.” Small Business Economics, 48(2), 2017, 331-343.

Ang, J. “Culture, Legal Origins and Financial Development.” Economic Inquiry, 57(2), 2019, 1016-1037.

Argote, L., P. Goodman and D. Schkade. “The Human Side of Robotics: How Workers React to a Robot.” Sloan Management Review, 1983

Arrow, K. "Information Dynamics in the Networked World.” Information Systems Frontiers, 5(1), 2003, 5-5.

Arrow, K. "Knowledge, Belief and the Economic System.” WIFO Monatsberichte, 86(12), 2013, 943-951.

Arrow, K., K.Bilir and A. Sorensen. "The Impact of Information Technology on the Diffusion of New Pharmaceuticals.” NBER Working Papers \#23257, 2017.

Autor, D. “The “Task Approach” to Labor Markets: An Overview.” Journal for Labour Market Research, 46(3), 2013, 185-199.

Autor, D. "Why Are There Still So Many Jobs? The History and Future of Workplace Automation." Journal of Economic Perspectives, 29(3), 2015, 3-30.

Autor, D., F. Levy, and R.J. Murnane. "The Skill Content of Recent Technological Change: An Empirical Exploration.” Quarterly Journal of Economics, 118(4), 2003, 1279-1333. 
Bansak, C, N. Morin and M. Starr. “Technology, Capital Spending and Capacity Utilization.” Economic Inquiry, 5(3), 2007, 631-645.

Benston, G. "Universal banking.” Journal of Economic Perspectives, 8(3), 1994, 121-143

Berger, A. "Comment on Diffusion of Financial Innovations: The Case of Junk Bonds and Note Issuance Facilities", Journal of Money, Credit and Banking, 28(3), 1996.

Borghans, L., B. H. H. Golsteyn, J. Heckman and H. Meijers. "Gender differences in risk aversion and ambiguity aversion.” NBER working paper, \#14713, 2009.

Caselli, F. and A. Manning. "Robot Arithmetic: Can New Technology Harm All Workers or the Average Worker?" CEP Discussion Paper \#1497, 2017.

Coleman, J., E. Katz and H. Menzel. “The diffusion of an innovation among physicians.” Sociometry, 20(4), 1957, 253-270.

Collard, D. "Pigou on Expectations and the Cycle, Source.” Economic Journal, 93(370), 1983, 411-414.

Cont. "Model Uncertainty and Its Impact on the Pricing of Derivative Instruments." Mathematical Finance, 16(3), 2006, 519-547.

Costa-Font, J. and M. Macis. "Social Economics: Current and Emerging Avenues” in Costa-Font, J. and M. Macis, Social Economics: Current and Emerging Avenues, MIT Press. 2017

Dabla-Norris, E., E. Kersting and G. Verdier. "Firm Productivity, Innovation, and Financial Development." Southern Economic Journal, 79(2), 2012, 422-449.

Demirgüç-Kunt, A. and E. Kane. "Deposit Insurance Around the Globe: Where Does It Work?” Journal of Economic Perspectives, 16(2), 2002, 175-195.

Eugster, B., R. Lalive, A. Steinhauer and J. Zweimuller. "Culture, work attitudes and job search: evidence from the swizz language border.” Journal of the European Economic Association, 15(5), 2017, 1056-1100

Fehr, E. and K. Hoff. "Introduction: Tastes, Castes and Culture: The Influence of Society on Preferences."

Economic Journal, 121(556), 2011, 396-396.

Fein, M. Regulatory focus on Robo Advisors, SSRN Paper: 3028259, 2017.

Fisch, J., M. Laboure and J. Turner. "The Economics of Complex Decision Making: The Emergence of the Robo Adviser," University of Pennsylvania Law School - Institute for Law and Economics, 2017

Frame, S. and L. White. "Empirical Studies of Financial Innovation: Lots of Talk, Little Action?” Journal of Economic Literature, 42(1), 2014, 116-144.

Frey, C. and M. Osborne. "The future of employment: how susceptible are jobs to computerisation?" Technological Forecasting and Social Change, 114(C), 2017, 254-280.

Galasso, V. and P. Profeta. "When the State Mirrors the Family: The Design of Pension Systems", Journal of the European Economic Association, jvx046, https://doi.org/10.1093/jeea/jvx046, 2018

Gelman, A. and J. Hill. "Data Analysis Using Regression and Multilevel/Hierarchical Models.” Cambridge University Press, 2007.

Goldstein, H. and J. Rasbash, "Improved approximations for multilevel models with binary responses." Journal of the Royal Statistical Society: Series A (Statistics in Society), 159(3), 1996, 505-513.

Greenwood, R. and D. Scharfstein. “The growth of finance.” Journal of Economic Perspectives, 27(2), $2013,3-28$.

Grosjean, P. "The institutional legacy of the Ottoman Empire: Islamic rule and financial development in South Eastern Europe.” Journal of Comparative Economics, 39(1), 2011, 1-16.

Grosjean, P. “A History of Violence: The Culture of Honor as a Determinant of Homicide in the US South.” Journal of the European Economic Association, 12(5), 2014, 1285-1316 
Guiso, L., P. Sapienza and L. Zingales. “Does culture affect economic outcomes.” Journal of Economic Perspective, 20, 2006, 23-48

Guiso, L., P. Sapienza and L. Zingales. "Cultural biases in economic exchange?” Quarterly Journal of Economics, 124(3), 2009, 1095-131.

Hahn, F.R. "Culture, geography and institutions: Empirical evidence from small-scale banking”, Economic Journal, 124, 2014, 859-886.

Hall, E. T. The hidden dimension, New York: Doubleday, 1966.

Ivanyna, M., A. Moumouras and P. Rangazas. "The Culture of Corruption, Tax Evasion, and Economic Growth." Economic Inquiry, 54(1), 2016, 520-542.

Jackson, M. "Networks in the Understanding of Economic Behaviors.” Journal of Economic Perspectives, 28(4, Fall), 2014, 3-22.

Jensen, R. “Adoption and diffusion of an innovation of uncertain profitability.” Journal of Economic Theory, 27(1), 1982, 182-193.

Kahneman, D. and A. Tversky. "Prospect Theory: An Analysis of Decision under Risk.” Econometrica, 47, 1979, 263-291.

Keynes, J. M. The General Theory of Employment, Interest and Money, Palgrave Macmillan, 1936

Kim, H.K., R. Maurer and O.S. Mitchell. "Time is Money: Rational Life Cycle Inertia and the Delegation of Investment Management.” Journal of Financial Economics, 121(2), 2016, 427-447.

Klasing, M. and P. Milionis. “Cultural Constraints on Innovation-Based Growth.” Economic Inquiry, 52(2), 2014, 796-810.

Knack, S. and P. Keefer. "Does social capital have an economic payoff? A cross-country investigation." Quarterly Journal of Economics, 112(4), 1997, 1251-88.

Knight, F. H. Risk, uncertainty and profit, Houghton Mifflin, Boston, Mass., 1921.

Kontot, K., J. Hamali and A. Firdaus. "Determining Factors of Customers” Preferences: A Case of Deposit Products in Islamic Banking?” Procedia - Social and Behavioral Sciences, 224, 2016, 167-175

Lam, J. and Swensen. Robo-Advisors: A Portfolio Management Perspective, manuscript, 2016

Lehmer, F. and M. Janser. “The Impact of Investments in New Digital Technologies on Wages - Worker-level Evidence from Germany?" Manuscript presented at SES, 2018

Leibbrandt, A., U. Gneezy and J. List. "Rise and fall of competitiveness in individualistic and collectivistic societies." Proceedings of the National Academy of Science, 110(23), 2013, 9305-9308.

Leppälä, S. “Arrow”s Paradox and Markets for Nonproprietary Information.” Cardiff Economics Working Papers \#E2013/2, 2013.

Ludwig, L. “The Rise of the Robo-Advisors - Should You Use One?”, InvestorJunkie, https://investorjunkie.com/35919/robo-advisors/, 2017

Mansfield, E. Industrial Research and Technological Innovation, Norton, New York, 1968.

Morikawa, M. "Firms Expectations about the Impact of AI and Robotics: Evidence from a Survey." Economic Inquiry, 55(2), 2017, 1054-1063.

Mohan, D., J. Ranger, W. Higham, T. Bailey and C. Gledhill. Trust in Technology, Independent Report for HSBC Bank, 2017.

Moody, J. “The Importance of Relationship Timing for Diffusion.” Social Forces, 81(1), 2002, 25-56

Moriconi, S. and G. Peri. “Country-Specific Preferences and Employment Rates in Europe.” NBER Working Paper No. 21561, 2015. 
Mullainathan, S., M. Noth and A. Schoar. "The Market for Financial Advice: An Audit Study.” National Bureau of Economic Research Working Paper \#17929, 2011.

Nelson, R. and S. Winter. An Evolutionary Theory of Economic Change, Cambridge: The Belknap Press of Harvard University Press, 1982

Nilsson, N. Artificial Intelligence: A New Synthesis. Morgan Kaufmann, 1998

Patsiotis, A., Hughes, T. and Webber, Don J. 'An examination of consumers' resistance to computer-based technologies,' Journal of Services Marketing, 27(4), 2013, pp. 294-312,

Pigou, A. C. Industrial Fluctuations, Macmillan, 1927

Poole, D., A. Mackworth and R. Goebel. Computational Intelligence A Logical Approach, Oxford University Press, New York, 1998.

Restuccia, D. and R. Rogerson. “The Causes and Costs of Misallocation.” Journal of Economic Perspectives, 31(3), 2017, 151-174

Rogers, C. R. “Toward a Modern Approach to Values: The Valuing Process in the Mature Person.” Journal of Abnormal and Social Psychology, 68(2), 1964, 160-167

Rogoff, K. “International Institutions for Reducing Global Financial Instability.” Journal of Economic Perspectives, 13(4), 1999, 21-42.

Savini, F. "Planning, uncertainty and risk: The neoliberal logics of Amsterdam urbanism.” Environment and Planning A, 49(4), 2017, 857-875.

Scitovsky, T. The Joyless Economy: An Inquiry into Human Satisfaction and Consumer, Dissatisfaction. Oxford: Oxford University Press, 1976

Schiller, R. "Narrative Economics,” American Economic Review, 107(4), 2017, 967-1004.

Shackle, G. L. S. Expectation in Economics, University Press: Cambridge, 1949[1952].

Shin, J.K. and C. Subramanian. “Asset Price Bubbles and Technological Innovation.” Economic Inquiry, 57(1), 2019, 482-497.

Snijders, T. and R. Bosker. "Multilevel Analysis: An Introduction to Basic and Advanced Multilevel Modelling." Second Edition. Sage. 2012.

Susskind, D. "Re-Thinking the Capabilities of Machines in Economics.” University of Oxford, Department of Economics, Discussion Paper Series, \#825, 2017.

Tabellini, G. "Culture and institutions - economic development in the regions of Europe.” Journal of the European Economic Association, 8(4), 2010, 677-716.

Tadesse, B. and E. K. Shukralla. "The impact of foreign direct investment on horizontal export diversification: Empirical evidence.” Applied Economics 45, 2013, 141-59.

Torta, E., E.van Dijk, P. Ruijten and R. Cuijpers. “The Ultimatum Game as Measurement Tool for Anthropomorphism in Human-Robot Interaction.” International Conference on Social Robotics ICSR 2013, Social Robotics, 209-217, 2017

Tubadji, A. "Value Free Analysis of Values: A Culture Based Development Approach," Sustainability, forthcoming, 2020.

Tubadji, A. "IKIGAI: a local or universal factor for happiness and productivity?” Manuscript, 2018.

Tubadji, A. "Was Weber right? The cultural capital roots of economic growth.” International Journal of Manpower, Special Issue on Culture and Labour, 35(1/2): 2014, 56-88.

Tubadji, A. “"Culture-Based Development: Culture and Institutions - Economic Development in the Regions of Europe.” International Journal of Society Systems Science, 5(4), 2013, 355-391. 
Tubadji, A. "Culture-Based Development: Empirical Evidence for Germany.” International Journal of Social Economics, 39(9), 2012, $690-703$.

Tubadji, A., R. Huggins and P. Nijkamp. "Firm Survival as a Function of Individual and Local Uncertainties: An Application of Shackle”s Potential Surprise Function.” Journal of Economic Issues, 2020.

Tubadji, A. and P. Nijkamp. "Six degrees of cultural diversity and R\&D output efficiency: cultural percolation of new ideas.” Letters in Spatial and Resource Sciences, 9(3), 2016, 247-264.

Verdier, T. and Y. Zenou. "The role of social networks in cultural assimilation.” Journal of Urban Economics, 97(C), 2017, 15-39.

von Hippel, E. The Sources of Innovation, Oxford: Oxford University Press, 1988.

Zak, P. and S. Knack. “Trust and growth.” Economic Journal, 111(470), 2001, 295-321 
Table 1: Robo-advisory adoption - OLS and Probit with country fixed effects

\begin{tabular}{|c|c|c|c|c|c|c|c|c|c|c|c|c|c|c|c|c|c|c|}
\hline \multirow{4}{*}{$\begin{array}{l}\text { Method } \\
\text { Dep. Var. }\end{array}$} & \multicolumn{15}{|c|}{ OLS } & \multicolumn{3}{|c|}{ Probit } \\
\hline & \multicolumn{3}{|c|}{ Spec. 1} & \multicolumn{3}{|c|}{ Spec. 2} & \multicolumn{3}{|c|}{ Spec. 3} & \multirow{2}{*}{\multicolumn{3}{|c|}{ Spec. 4}} & \multirow{2}{*}{\multicolumn{3}{|c|}{ Spec. 5}} & \multirow{2}{*}{\multicolumn{3}{|c|}{$\begin{array}{c}\text { Spec. } 6 \\
\text { ROBO_FAN }\end{array}$}} \\
\hline & & & & & & & \multirow{2}{*}{\multicolumn{3}{|c|}{$\begin{array}{l}\text { ROBO_FAN_count } \\
\text { coef. t-values }\end{array}$}} & & & & & & & & & \\
\hline & coef. & t-value & & coef. & t-values & & & & & coef. & \multicolumn{2}{|c|}{ t-values } & coef. & \multicolumn{2}{|l|}{ t-values } & $\mathrm{dy} / \mathrm{dx}$ & z-values & \\
\hline quantity_use & 0.298 & 18.34 & $* * *$ & 0.267 & 11.26 & $* * *$ & 0.275 & 15.54 & $* * *$ & 0.298 & 18.28 & $* * *$ & 0.298 & 18.28 & $* * *$ & 0.085 & 19.11 & $* * *$ \\
\hline access_before 2014 & -0.099 & -2.75 & $* * *$ & & & & -0.083 & -2.17 & * & -0.098 & -2.75 & $* * *$ & -0.099 & -2.75 & $* * *$ & -0.026 & -2.69 & $* * *$ \\
\hline time_access & & & & -0.048 & -2.49 & $* *$ & & & & & & & & & & & & \\
\hline age & 0.023 & 4.25 & $* * *$ & 0.027 & 3.53 & $* * *$ & 0.019 & 3.26 & $* * *$ & 0.023 & 3.88 & $* * *$ & 0.023 & 3.81 & $* * *$ & 0.006 & 3.15 & $* * *$ \\
\hline age_sq & -0.0003 & -5.21 & $* * *$ & -0.0004 & -3.94 & $* * *$ & -0.0003 & -4.42 & $* * *$ & -0.0003 & -4.89 & $* * *$ & -0.0003 & -4.82 & $* * *$ & -0.0001 & -4.20 & $* * *$ \\
\hline male & 0.164 & 6.14 & $* * *$ & 0.164 & 4.61 & $* * *$ & 0.160 & 5.57 & $* * *$ & 0.164 & 6.14 & $* * *$ & 0.163 & 6.05 & $* * *$ & 0.070 & 9.16 & $* * *$ \\
\hline$h c$ & 0.080 & 2.83 & $* * *$ & 0.093 & 2.49 & $* *$ & 0.032 & 1.02 & & 0.080 & 2.82 & $* * *$ & 0.079 & 2.80 & $* * *$ & 0.047 & 5.79 & $* * *$ \\
\hline income & & & & & & & 0.033 & 5.47 & $* * *$ & & & & & & & & & \\
\hline alone & -0.050 & -1.70 & & -0.071 & -1.76 & & -0.018 & -0.55 & & -0.050 & -1.70 & & -0.050 & -1.68 & & -0.019 & -2.27 & $*$ \\
\hline retired & 0.041 & 0.83 & & -0.059 & -0.73 & & 0.059 & 1.09 & & 0.042 & 0.84 & & 0.039 & 0.76 & & 0.011 & 0.73 & \\
\hline student & & & & & & & & & & 0.004 & 0.06 & & -0.0003 & 0.00 & & -0.007 & -0.37 & \\
\hline part_time & & & & & & & & & & & & & -0.019 & -0.42 & & -0.008 & -0.57 & \\
\hline country_FE & YE & ES & & YE & ES & & & ES & & $\mathrm{YE}$ & ES & & & ES & & & ES & \\
\hline R-squared & & 0.12 & & & 0.08 & & & 0.12 & & & 0.12 & & & 0.12 & & & $.12(p s)$ & \\
\hline $\mathrm{N}$ obs & & 8031 & & & 4946 & & & 7012 & & & 8031 & & & 8031 & & & 11135 & \\
\hline
\end{tabular}

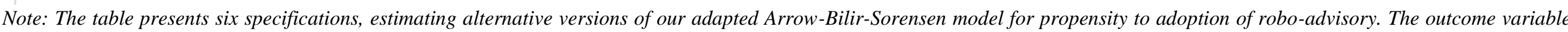

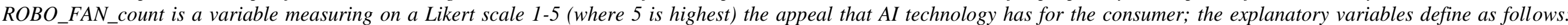

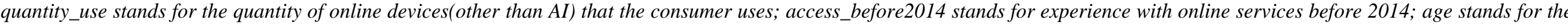

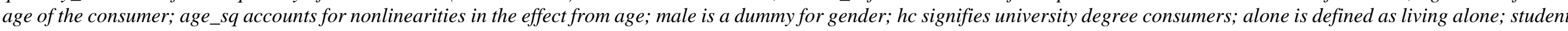

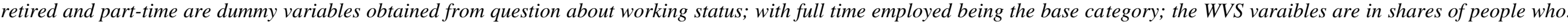

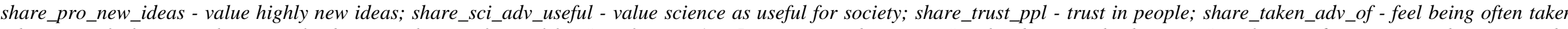

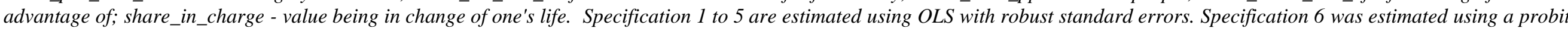

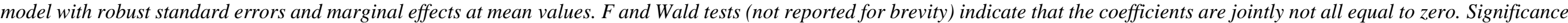
level: * $p<0.1$; ** $p<0.05$; *** $p<0.01$. 
Table 2: A CBD model for robo-advisory and culture - OLS with WVS proxies for culture

\begin{tabular}{|c|c|c|c|c|c|c|c|c|c|c|c|c|c|c|c|}
\hline \multirow{3}{*}{$\begin{array}{l}\text { Method } \\
\text { Dep. Var. }\end{array}$} & \multicolumn{15}{|c|}{ OLS } \\
\hline & \multicolumn{3}{|c|}{ Spec. 1} & \multicolumn{3}{|c|}{ Spec. 2} & \multicolumn{3}{|c|}{ Spec. 3} & \multicolumn{3}{|c|}{ Spec. 4} & \multicolumn{3}{|c|}{ Spec. 5} \\
\hline & coef. & t-values & & coef. & t-values & & $\begin{array}{l}\text { ROBO } \\
\text { coef. }\end{array}$ & $\begin{array}{l}\text { FAN_co } \\
\text { t-values }\end{array}$ & unt & coef. & t-values & & coef. & t-values & \\
\hline quantity_use & 0.297 & 15.32 & $* * *$ & 0.298 & 18.42 & $* * *$ & 0.305 & 18.92 & $* * *$ & 0.319 & 19.04 & $* * *$ & 0.306 & 19.04 & $* * *$ \\
\hline access_before 2014 & -0.018 & -0.40 & & -0.088 & -2.43 & $* *$ & -0.085 & -2.35 & $* *$ & -0.062 & -1.63 & & -0.079 & -2.19 & * \\
\hline age & 0.032 & 4.26 & $* * *$ & 0.022 & 3.53 & $* * *$ & 0.022 & 3.63 & $* * *$ & 0.023 & 3.47 & $* * *$ & 0.023 & 3.72 & $* * *$ \\
\hline$a g e \_s q$ & -0.0004 & -5.26 & $* * *$ & -0.0003 & -4.72 & $* * *$ & -0.0003 & -4.78 & $* * *$ & -0.0003 & -4.73 & $* * *$ & -0.0003 & -5.01 & $* * *$ \\
\hline male & 0.106 & 3.17 & $* * *$ & 0.157 & 5.74 & $* * *$ & 0.159 & 5.83 & $* * *$ & 0.151 & 5.29 & $* * *$ & 0.150 & 5.49 & $* * *$ \\
\hline$h c$ & 0.146 & 4.27 & $* * *$ & 0.124 & 4.41 & $* * *$ & 0.111 & 3.93 & $* * *$ & 0.138 & 4.71 & $* * *$ & 0.146 & 5.26 & $* * *$ \\
\hline alone & -0.080 & -2.16 & $*$ & -0.075 & -2.54 & $* *$ & -0.073 & -2.46 & $*$ & -0.067 & -2.12 & $*$ & -0.083 & -2.77 & $* *$ \\
\hline student & 0.004 & 0.06 & & -0.010 & -0.17 & & -0.005 & -0.08 & & 0.003 & 0.04 & & 0.009 & 0.15 & \\
\hline retired & 0.136 & 2.13 & $*$ & 0.043 & 0.83 & & 0.041 & 0.80 & & 0.073 & 1.37 & & 0.071 & 1.37 & \\
\hline part_time & -0.101 & -1.68 & & -0.046 & -1.00 & & -0.032 & -0.70 & & -0.033 & -0.70 & & -0.063 & -1.39 & \\
\hline share_pro_new_ideas & -1.280 & -3.09 & $* * *$ & & & & & & & & & & & & \\
\hline share_sci_adv_useful & & & & 0.671 & 6.08 & $* * *$ & & & & & & & & & \\
\hline share_trust_ppl & & & & & & & -0.854 & -6.73 & $* * *$ & & & & & & \\
\hline share_taken_adv_of & & & & & & & & & & 1.941 & 7.66 & $* * *$ & & & \\
\hline share_in_charge & & & & & & & & & & & & & 0.068 & 0.61 & \\
\hline cons & 1.744 & 9.76 & $* * *$ & 1.432 & 10.02 & $* * *$ & 1.919 & 13.62 & $* * *$ & 1.450 & 9.69 & $* * *$ & 1.652 & 11.09 & $* * *$ \\
\hline R-squared & & 0.09 & & & 0.10 & & & 0.10 & & & 0.11 & & & 0.09 & \\
\hline $\mathrm{N}$ obs & & 5478 & & & 8031 & & & 8031 & & & 7312 & & & 8031 & \\
\hline
\end{tabular}

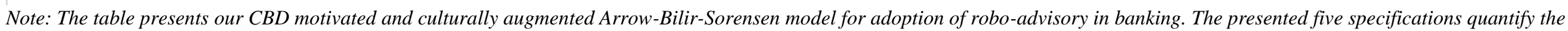

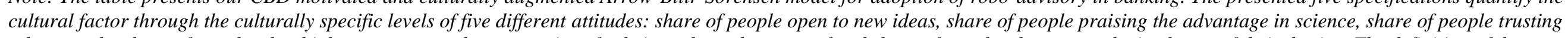

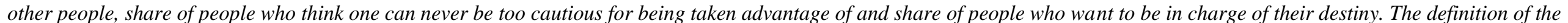

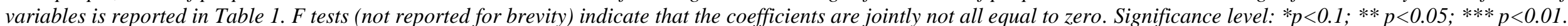


Table 3: Hierarchical CBD model for cultural bias in adoption of AI in the banking sector

\begin{tabular}{|c|c|c|c|c|c|c|c|c|c|c|c|c|c|c|c|c|c|c|}
\hline \multirow[t]{2}{*}{ dep. var. } & \multicolumn{18}{|c|}{ ROBO_FAN_count } \\
\hline & coef. & \multicolumn{2}{|l|}{ z-value } & coef. & \multicolumn{2}{|l|}{$z$-value } & coef. & \multicolumn{2}{|l|}{ z-value } & coef. & z-value & & coef. & \multicolumn{2}{|l|}{$z$-value } & coef. & \multicolumn{2}{|l|}{ z-value } \\
\hline \multicolumn{19}{|l|}{ Fixed Compnent } \\
\hline quantity_use & 0.298 & 19.28 & $* * *$ & 0.286 & 15.29 & $* * *$ & 0.298 & 19.25 & $* * *$ & 0.298 & 19.28 & $* * *$ & 0.303 & 18.93 & $* * *$ & 0.298 & 19.29 & $* * *$ \\
\hline access_before 2014 & -0.098 & -2.84 & $* * *$ & -0.032 & -0.79 & & -0.098 & -2.85 & $* * *$ & -0.098 & -2.84 & $* * *$ & -0.098 & -2.71 & $* *$ & -0.098 & -2.83 & $* * *$ \\
\hline age & 0.023 & 3.66 & $* * *$ & 0.034 & 4.31 & $* * *$ & 0.023 & 3.66 & $* * *$ & 0.023 & 3.66 & $* * *$ & 0.024 & 3.52 & $* * *$ & 0.023 & 3.67 & $* * *$ \\
\hline age_sq & -0.0003 & -4.54 & $* * *$ & -0.0004 & -4.96 & $* * *$ & -0.0003 & -4.54 & $* * *$ & -0.0003 & -4.54 & $* * *$ & -0.0003 & -4.43 & $* * *$ & -0.0003 & -4.55 & $* * *$ \\
\hline male & 0.162 & 6.02 & $* * *$ & 0.117 & 3.56 & $* * *$ & 0.162 & 6.02 & $* * *$ & 0.162 & 6.02 & $* * *$ & 0.160 & 5.63 & $* * *$ & 0.162 & 6.02 & $* * *$ \\
\hline hc & 0.082 & 2.93 & $* * *$ & 0.084 & 2.45 & $* *$ & 0.083 & 2.96 & $* * *$ & 0.082 & 2.93 & $* * *$ & 0.099 & 3.35 & $* * *$ & 0.082 & 2.93 & $* * *$ \\
\hline alone & -0.051 & -1.72 & & -0.058 & -1.58 & & -0.051 & -1.71 & & -0.051 & -1.72 & & -0.051 & -1.63 & & -0.051 & -1.72 & \\
\hline student & 0.000 & 0.00 & & -0.001 & -0.02 & & 0.000 & -0.01 & & 0.000 & 0.00 & & 0.003 & 0.05 & & 0.000 & 0.01 & \\
\hline retired & 0.040 & 0.77 & & 0.106 & 1.66 & & 0.040 & 0.77 & & 0.040 & 0.77 & & 0.052 & 0.95 & & 0.040 & 0.77 & \\
\hline part_time & -0.021 & -0.46 & & -0.056 & -0.92 & & -0.023 & -0.49 & & -0.021 & -0.46 & & -0.018 & -0.38 & & -0.021 & -0.46 & \\
\hline _cons & 1.648 & 10.94 & $* * *$ & 1.528 & 8.31 & $* * *$ & 1.594 & 10.84 & $* * *$ & 1.648 & 10.94 & $* * *$ & 1.587 & 10.32 & $* * *$ & 1.648 & 10.99 & $* * *$ \\
\hline \multicolumn{19}{|l|}{ Random Effects } \\
\hline & coef. [ & \multicolumn{2}{|c|}{ [95\% Conf. Inter.] } & coef. & \multicolumn{2}{|c|}{ [95\% Conf. Inter.] } & coef. & \multicolumn{2}{|c|}{ [95\% Conf. Inter.] } & coef. & \multicolumn{2}{|c|}{ [95\% Conf. Inter.] } & coef. & \multicolumn{2}{|c|}{ [95\% Conf. Inter.] } & coef. & \multicolumn{2}{|c|}{ [95\% Conf. Inter.] } \\
\hline sd(share_pro_new_ideas) & & & & 1.47E-05 & $2.13 \mathrm{E}-13$ & 1008.99 & & & & & & & & & & & & \\
\hline sd(share_sci_adv_useful) & & & & & & & 0.526 & 0.34 & 0.82 & & & & & & & & & \\
\hline sd(share_trust_ppl) & & & & & & & & & & $9.38 \mathrm{E}-08$ & $5.52 \mathrm{E}-13$ & 0.02 & & & & & & \\
\hline$s d($ share_taken_adv_of) & & & & & & & & & & & & & 1.783 & 1.11 & 2.86 & & & \\
\hline sd(share_in_charge) & & & & & & & & & & & & & & & & 0.296 & 0.04 & 2.04 \\
\hline$s d$ (_cons) & 0.205 & 0.13 & 0.32 & 0.195 & 0.11 & 0.34 & $6.41 \mathrm{E}-05$ & $4.30 \mathrm{E}-158$ & $9.60 E+148$ & 0.205 & 0.13 & 0.32 & 2.67E-06 & $8.32 \mathrm{E}-13$ & 8.54 & 0.128 & 0.01 & 1.98 \\
\hline sd(Residual) & 1.192 & 1.17 & 1.21 & 1.206 & 1.18 & 1.23 & 1.192 & 1.17 & 1.21 & 1.192 & 1.17 & 1.21 & 1.197 & 1.18 & 1.22 & 1.192 & 1.17 & 1.21 \\
\hline $\mathrm{N}$ obs & & 8031 & & & 5478 & & & 8031 & & & 8031 & & & 7312 & & & 8031 & \\
\hline $\mathrm{N}$ groups & & 11 & & & 7 & & & 11 & & & 11 & & & 10 & & & 11 & \\
\hline obs per group min & & 462 & & & 719 & & & 462 & & & 462 & & & 462 & & & 462 & \\
\hline obs per group max & & 909 & & & 909 & & & 909 & & & 909 & & & 909 & & & 909 & \\
\hline Prob > chi2 & & 0.0000 & & & 0.0000 & & & 0.0000 & & & 0.0000 & & & 0.0000 & & & 0.0000 & \\
\hline LR test & & 0.0000 & & & 0.0000 & & & 0.0000 & & & 0.0000 & & & 0.0000 & & & 0.0000 & \\
\hline
\end{tabular}

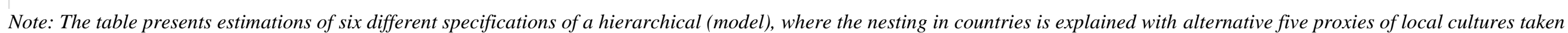
from the WVS, as listed in Table 3. The definition of the variables is reported in Table 1. Significance level: *p<0.1; **p<0.05; ***p<0.01.. 
Appendix: Main variables and their definitions

\begin{tabular}{|c|c|c|c|c|c|c|c|c|c|}
\hline $\begin{array}{c}\text { Model } \\
\text { Component }\end{array}$ & Var & Source & Question in survey & Description & Obs & Mean & St. Dev. & Mim & Max \\
\hline \multirow{2}{*}{$\begin{array}{l}\text { Propensity to } \\
\text { adopt Al } \\
\text { (Outcome) }\end{array}$} & $R O B O \_F A N$ & ING & $\begin{array}{l}\text { Would you allow a Robo- } \\
\text { Advisor to make financial } \\
\text { decisions for you? }\end{array}$ & $\begin{array}{l}\text { This is a dichotomous variable based on } R O B O_{-} F A N_{-} \text {count, which is } \\
\text { based on } 5 \text { possible answers. For } R O B O_{-} F A N \text { to be given a value of } 1 \text {, the } \\
\text { response was either "Yes, if the decisions need final approval from me" or } \\
\text { "Yes, I would like a computer programme to make decisions and conduct } \\
\text { financial activities for me on my behalf without needing my approval" and } 0 \\
\text { otherwise }\end{array}$ & 11,135 & 0.21 & 0.41 & 0 & 1 \\
\hline & $R O B O O_{-} F A N_{-}$count & ING & $\begin{array}{l}\text { Would you allow a Robo- } \\
\text { Advisor to make financial } \\
\text { decisions for you? }\end{array}$ & $\begin{array}{l}\text { This variable is based on a Likert scale with a value of } 5 \text { if the respondent } \\
\text { chose "Yes, I would like a computer programme to make decisions and } \\
\text { conduct financial activities for me on my behalf without needing my } \\
\text { approval", descending to } 4 \text { if the respondent chose "Yes, if the decisions } \\
\text { need final approval from me" all the way to } 0 \text { (zero) if the respondent chose } \\
\text { "No". }\end{array}$ & 11,135 & 2.36 & 1.27 & 1 & 5 \\
\hline \multirow{2}{*}{$\begin{array}{l}\mathrm{Z} \\
\text { (experienced in } \\
\text { being in the } \\
\text { online } \\
\text { environment } \\
\text { when AI was } \\
\text { introduced) }\end{array}$} & access_before_2014 & ING & $\begin{array}{l}\text { When did you begin } \\
\text { using mobile banking on } \\
\text { your mobile } \\
\text { phone/tablet/wearable } \\
\text { device for the first time? }\end{array}$ & $\begin{array}{l}\text { The variable } A C C E S S S B E F O R E \_2 O 14 \text { is a dummy variable equal to } 1 \text { (one) if } \\
\text { the individual used online banking before the year } 2014 \text {, and } 0 \text { (zero) } \\
\text { otherwise. This dummy variable is based on the question 'How long have you } \\
\text { been using online banking?', which has four answers: before } 2014,2015,2016 \text {, } \\
\text { and } 2017 \text {. }\end{array}$ & 11,135 & 0.21 & 0.4 & 0 & 1 \\
\hline & time_access & ING & $\begin{array}{l}\text { When did you begin } \\
\text { using mobile banking on } \\
\text { your mobile } \\
\text { phone/tablet/wearable } \\
\text { device for the first time? }\end{array}$ & $\begin{array}{l}\text { We use the question underlying variable } A C C E S S S_{-} B E F O R E \_2014 \text { also as a } \\
\text { foundation for the categorical variable called } T I M E_{-} A C C E S S \text { where } 2017 \text { is } \\
\text { equal to } 1,2016 \text { to } 2,2015 \text { to } 3 \text { and before } 2014 \text { to } 4 \text {. }\end{array}$ & 6,252 & 2.94 & 0.97 & 1 & 4 \\
\hline $\begin{array}{l}\mathrm{N} \\
\text { (volume of } \\
\text { digital use } \\
\text { other than } \mathrm{Al} \text { ) }\end{array}$ & quantity_use & ING & $\begin{array}{l}\text { Please check all items } \\
\text { you own: } \\
\text { Have you ever done } \\
\text { your banking on a: } \\
\text { mobile } \\
\text { phone/tablet/wearable } \\
\text { device/none of these }\end{array}$ & $\begin{array}{l}\text { QUANTITY_USE is based on two types of questions: (i) whether the } \\
\text { consumer uses a mobile phone, a smart phone, a tablet, a smart TV, and or an } \\
\text { Apple wearable device, and (ii) whether the consumer has used these devices } \\
\text { for online banking. The interaction between possessing each device and } \\
\text { having used each individual device for online banking is equal to } 1 \text { (one) only } \\
\text { when the person has answered yes to both questions, and we sum the } \\
\text { interactions across the devices for each person. The sum of these interactions } \\
\text { per person allows us to generate a variable called QUANTITY USE, which } \\
\text { provides a strong indication of the quantity of devices used for online } \\
\text { banking by the individual. }\end{array}$ & 11,135 & 0.89 & 0.95 & 0 & 5 \\
\hline \multirow{5}{*}{$\begin{array}{l}\text { CV } \\
\text { (cultural value } \\
\text { i.e. cultural } \\
\text { attitudes) }\end{array}$} & $\begin{array}{c}\text { SHARE_SCI_ADV_UUSE } \\
F U \mathcal{L} \\
\end{array}$ & wvs & $\begin{array}{l}\text { Opinion about scientific } \\
\text { advances }\end{array}$ & $\begin{array}{l}\text { Constructed as a dichotomous variable for those who believe that scientific } \\
\text { advances are generally useful. Those who disagree with the statement were } \\
\text { given a value of } 0 \text {. }\end{array}$ & 11,135 & 0.4 & 0.13 & 0.14 & 0.66 \\
\hline & $\begin{array}{l}\text { SHARE_PRONEW_IDE } \\
\qquad A S \\
\end{array}$ & .wvs & $\begin{array}{l}\text { It is important for this } \\
\text { person to think up new } \\
\text { ideas and be creative }\end{array}$ & $\begin{array}{l}\text { Constructed as a dichotomous variable for those who are in favour of novel } \\
\text { ideas. Those who disagree with the statement were given a value of } 0 \text {. }\end{array}$ & 7,110 & 0.13 & 0.04 & 0.09 & 0.22 \\
\hline & $S H A R E \_T R U S T+P P L$ & wvs & $\begin{array}{l}\text { Trust: Other people in } \\
\text { country }\end{array}$ & $\begin{array}{l}\text { A dichotomous variable constructed from a Likert scale response. Those who } \\
\text { answered } 7 \text { or above (trusting) were coded with } 1 \text {, and below } 7 \text { (not trusting) } \\
\text { coded with a } 0 \text {. }\end{array}$ & 11,135 & 0.28 & 0.12 & 0.12 & 0.58 \\
\hline & $\begin{array}{c}\text { SHARE_TAKEN_ADV } \\
O F\end{array}$ & wvs & $\begin{array}{l}\text { Do you think most } \\
\text { people take advantage of } \\
\text { you? }\end{array}$ & $\begin{array}{l}0 / 1 \text { variable constructed from Likert scale style responses. Those who } \\
\text { answered } 7 \text { or above (people take advantage of them) coded with a } 1 \text {, and } \\
\text { those below } 7 \text { (people do not take advantage of them) coded with a } 0 \text {. }\end{array}$ & 10,103 & 0.12 & 0.06 & 0.04 & 0.24 \\
\hline & $S H A R E \_I N \_C H A R G E$ & wvs & $\begin{array}{l}\text { How much freedom of } \\
\text { choice and control do } \\
\text { you like? }\end{array}$ & $\begin{array}{l}0 / 1 \text { variable constructed from Likert scale style responses. Those who } \\
\text { answered } 7 \text { or above (want to be in control) coded with a } 1 \text {, and those below } 7 \\
\text { (do not want to be in control) coded with a } 0 \text {. }\end{array}$ & 11,135 & 0.53 & 0.12 & 0.34 & 0.77 \\
\hline
\end{tabular}




\begin{tabular}{|c|c|c|c|c|c|c|c|c|c|}
\hline $\begin{array}{c}\text { Model } \\
\text { Component } \\
\end{array}$ & Var & Source & Question in survey & Description & Obs & Mean & St. Dev. & Mim & Max \\
\hline \multirow{9}{*}{$\begin{array}{l}\mathrm{X} \\
\text { (control } \\
\text { variable) }\end{array}$} & $M A L E$ & ING & What is your gender? & $\begin{array}{l}0 / 1 \text { variable which distinguishes between genders. Male is coded as } 1 \text {; female } \\
\text { is coded as } 0 .\end{array}$ & 11,135 & 0.49 & 0.5 & 0 & 1 \\
\hline & STUDENT & ING & $\begin{array}{l}\text { What is your working } \\
\text { status? }\end{array}$ & $\begin{array}{l}0 / 1 \text { variable for those in the survey who are students. If student, value of } 1 \text { is } \\
\text { given, any other employment type receives a value of } 0 \text {. }\end{array}$ & 11,135 & 0.07 & 0.25 & 0 & 1 \\
\hline & Part_time & ING. & $\begin{array}{l}\text { What is your working } \\
\text { status }\end{array}$ & $\begin{array}{l}.0 / 1 \text { variable for those in the survey who are part time workers. If working part } \\
\text { time, value of } 1 \text { is given, any other employment type receives a value of } 0 \text {. }\end{array}$ & 11,135 & 0.1 & 0.3 & 0 & 1 \\
\hline & RETIRED & ING & $\begin{array}{l}\text { What is your working } \\
\text { status }\end{array}$ & $\begin{array}{l}0 / 1 \text { variable for those in the survey who are retired. If retired, value of } 1 \text { is } \\
\text { given any other employment type receives a value of } 0 \text {. }\end{array}$ & 11,135 & 0.16 & 0.37 & 0 & 1 \\
\hline & ALONE & ING & $\begin{array}{l}\text { What is the current } \\
\text { composition of your } \\
\text { household? }\end{array}$ & $\begin{array}{l}\text { Constructed as a dichotomous variable. Any individuals who answered } \\
\text { "Single person household living alone" were given a value of } 1 \text { and all other } \\
\text { responses a value of } 0 \text {. }\end{array}$ & 11,135 & 0.33 & 0.47 & 0 & 1 \\
\hline & income & ING & $\begin{array}{l}\text { What is your average } \\
\text { take-home (net) monthly } \\
\text { household income? }\end{array}$ & Answer is provided as amounts in Euros. & 9,503 & 5.15 & 2.89 & 0 & 13 \\
\hline & $h c$ & ING & $\begin{array}{l}\text { What is the highest level } \\
\text { of education you have } \\
\text { completed? }\end{array}$ & $\begin{array}{l}\text { Constructed as a dichotomous variable where any other individuals were } \\
\text { given a value of } 0 \text {.except for individuals with Bachelor, Master or } \mathrm{PhD} \\
\text { University levels of education where given a value of } 1 \text {. }\end{array}$ & 11,135 & 0.39 & 0.49 & 0 & 1 \\
\hline & RATHER_CASH & ING & $\begin{array}{l}\text { If it were up to me, I } \\
\text { would rather buy from a } \\
\text { store where... }\end{array}$ & $\begin{array}{l}\text { Constructed as a dichotomous variable based on } 2 \text { possible answers: } \\
\text { Responses of "I could pay only with cash" were given a value of } 1 \text { and } \\
\text { responses of "I could pay only without cash (e.g. by card, mobile banking, } \\
\text { cheque, bank standing order, etc.)" were given a value of } 0 \text {. }\end{array}$ & 11,135 & 0.3 & 0.46 & 0 & 1 \\
\hline & $A G E$ & ING & What is your age? & Continuous variable from age $18-99$. & 11,135 & 44.25 & 15.3 & 18 & 99 \\
\hline
\end{tabular}

